\section{Exercise is Medicine Global Health Initiative for All Ages}

Received: February 28, 2017; Accepted: March 03, 2017; Published: March 07, 2017

\section{Zerf Mohammed \\ Physical Education Institute Laboratory, OPAPS University of Mostaganem, Mostaganem 27000, Algeria}

Supporting the use of physical exercises in preventing or managing existing physical and mental health problems. The literature proves that people with severe and enduring mental and physical health problems have a significantly increased risk of physical disorder and premature mortality.

Therefore, The Complete Guide to a benefit Physical Activity for Health, Mental and fitness requesting the inclusion of knowledge physical exercise (training or relaxation) as a Medicine (EIM) initiative introduced in 2007 to advance the implementation of evidence-based strategies to elevate the status of Physical activity in Healthcare [1], based on physical exercise as a physiological scientific profession with interests in sports training and exercise as medicine.

While Pediatrics Exercise Science and Medicine are the leading reference work in the field and are designed to support and challenge those involved in paediatrics sports science [2]. As well as any coach/physician or athletic/people trainer working with children and young people or ageing, to have a long and healthy life and to promote well-being and self-esteem.

Viewing the connection between Physical Activity and health has been clearly established and exercise should be viewed as a costeffective medication that is universally prescribed as a first line treatment for virtually every chronic disease [3].

Moreover, educating the nation to exercise regularly to enhance the safety lifestyle, request "The Recommended Quantity and Quality of Exercise for Developing and Maintaining body healthy for all age" [1]. Since this recommendation which required the design of a program for the individual to provide the proper amount of physical activity to attain maximal benefit at the lowest risk [4].

This in turn requires a monitoring and evaluation program based on the medical control that is very expensive for the majority of the population. Our addresses for the Scientific Committee to optimise models as guidance for people of all ages and levels fitness health, as well as health professionals to provide strategies founded on Physical Activity levels and clinical settings [5].

By mounting research data involved in a variety of physiological, psychological and pathophysiological processes, focusing on physical exercise science in relation to individual performance and to the diagnosis, management, and prevention of the

\author{
Corresponding author: \\ Zerf Mohammed \\ biomeca.zerf@outlook.com \\ Physical Education Institute Laboratory, \\ OPAPS University of Mostaganem, \\ Mostaganem 27000, Algeria.
}

Tel: 213773450124

Citation: Mohammed Z. Exercise is Medicine Global Health Initiative for All Ages. J Clin Epigenet. 2017, 3:1.

person's injuries, founded on new and evolving technology like smart phone applications, along with various websites and programs that have proven efficacy. Drawing on the experiences of scientists, researchers, practitioners and teachers in a wide range of sport and exercise settings.

\section{Conclusion}

Agreeing to Physical Activity and Health explains clearly, methodically and in detail the relationships between physical activity, health and sickness, and recognizes the benefits of exercise in the prevention and treatment of health conditions, not limited to its impact on aspects of physical health and disease states, but also its advantage to enhance various aspects of mental health, including emotional disorders. Our aims in this editorial paper follow-up the needed to ascertain the influence of the international community to counsel these practices. Where world organizations are the breath of the heart of these goals as well as the scientists to look at writing undergraduate offering to the interested readers knowledgeable by concerns and question centered on accessible style, which provide a good balance between theory and application to practice, put up on the biological basis of the ability to systems and processes within the sport practice came a healthy life and well-being. 


\section{References}

1 Lobelo F, Stoutenberg M, Hutber A (2014) The Exercise is Medicine Global Health Initiative: a 2014 update. Br J Sports Med 48: 16271633.

2 Sallis R, Franklin B, Joy L, Ross R, Sabgir D, et al. (2015) Strategies for promoting physical activity in clinical practice. Prog Cardiovasc Dis 57: 375-386.

3 Garber CE, Blissmer B, Deschenes MR, Franklin BA, Lamonte MJ, et al. (2011) American College of Sports Medicine. American College of Sports Medicine position stand. Quantity and quality of exercise for developing and maintaining cardiorespiratory, musculoskeletal, and neuromotor fitness in apparently healthy adults: guidance for prescribing exercise. Med Sci Sports Exerc.

4 Schweiz Z (1993) The recommended quantity and quality of exercise for developing and maintaining cardiorespiratory and muscular fitness in healthy adults. Position stand of the American College of Sports Medicine. Schweiz Z Sportmed 41: 127-137.

5 Patrick K, Pratt M, Sallis RE (2009) The healthcare sector's role in the U.S. national physical activity plan. J Phys Act Health 6: S211-S219. 